Gut, 1988, 29, 121-125

\title{
Manometric measurement of human sphincter of Oddi length
}

\author{
F I HABIB, E CORAZZIARI, D BILIOTTI, L PRIMERANO, A VISCARDI, \\ V SPERANZA, E DE MASI, G FEGIZ, AND A TORSOLI \\ From the Cattedra di Gastroenterologia I, Clinica Chirurgica VI, Clinica Chirurgica I, Universita' \\ 'La Sapienza' Roma, Italy
}

SUMmARY Length of biliary (CBD) and/or pancreatic (PD) sphincter of Oddi (SO) was measured during perendoscopic or intraoperative manometry in 21 control subjects and in 46 patients with biliary disease. When the high resting pressure (HPZ) and the phasic wave zone (PAZ) were considered, SO length was, in the control group, $9.5 \pm 0.5 \mathrm{~mm}(\mathrm{M} \pm \mathrm{SE})$ and $9.4 \pm 0.6 \mathrm{~mm}$ at the level of the CBD-SO, and $7.7 \pm 0.6 \mathrm{~mm}$ and $6.9 \pm 0.5 \mathrm{~mm}$ at the level of the PD-SO. The physiological sphincter length appeared substantially shorter than the anatomical one, as reported in the literature. No significant differences were found between controls and patients with CBD stones. Endoscopic sphincterotomy without manometry reduced mean sphincter length by $80 \cdot 6 \pm 5 \cdot 5 \%$ (mean $\pm \mathrm{SE}$ ) and this was increased to $95 \cdot 2 \pm 3.5 \%$ when the length of the sphincterotomy was tailored to the manometric findings. Surgical partial sphincterotomy reduced sphincter length by only $46 \cdot 7 \pm 10 \cdot 3 \%$.

The physiological length of the sphincter of Oddi (SO) may be measured manometrically. Manometric estimates vary from $3-14 \mathrm{~mm},{ }^{1-4}$ but this has not been systematically studied in man. In particular, information concerning the pancreatic sphincter is scanty. Autoptic (cast, histology, radiology) and $x$-ray in vivo measurements have reported that the biliary sphincter ranges from 8 to $20^{5-8}$ or even $27 \mathrm{~mm}$ in length, ${ }^{9}$ the pancreatic sphincter from 3.5 to $18 \mathrm{~mm}^{57810}$ and the ampullary sphincter from 0 to $12 \mathrm{~mm}^{5}$. $^{710}$

Knowledge of SO length may be of interest in understanding pancreaticobiliary diseases and may be useful during sphincterotomy. The aim of the present work was therefore to measure SO length in both the biliary and the pancreatic tract. Control subjects and patients with biliary disease were examined by perendoscopic or intraoperative manometry, in some instances before and after papillotomy.

Address for correspondence: Aldo Torsoli, MD, Cattedra di Gastroenterologia I, II Clinica Medica, Policlinico Umberto I, 00161 Roma, Italy.

Received for publication 2 July 1987.

\section{Methods}

SUBJECTS

Five groups of patients were investigated: Group I comprised 21 control subjects presenting with recurrent abdominal pain but without evidence of pancreatic or biliary disease; all had normal ERCP. Perendoscopic biliary sphincter manometry was performed in 11 subjects (four men; age 25-61 years) and pancreatic manometry was done in 10 subjects (nine women; age 25-50 years). Group 2 comprised 12 subjects (three men; age 28-66 years) with normal sphincter area at ERCP and manometry, six with no evidence of pancreaticobiliary disease and normal ERCP, four having gall bladder calculi, two with choledochal stones. An additional patient had undergone cholecystectomy. Each underwent pancreatic and biliary manometry carried out in random order. Group 3 comprised 19 patients presenting with common bile duct stones (10 men; age 21-83 years). Group 4 comprised 20 patients (nine men; age 14-77 years) who also had common bile duct stones and these were studied before and immediately after 
endoscopic sphincterotomy. Group 5 comprised 11 patients (five men; age 30-64 years) in whom common bile duct stones were removed surgically. Intraoperative manometry was carried out before and immediately after sphincterotomy.

The study was approved by the Ethical Committee of the Italian Society of Gastroenterology. All patients gave informed consent.

\section{PROTOCOL OF THE STUDY}

\section{Perendoscopic manometry}

Location of the catheter, in the common bile or pancreatic duct, was checked by fluoroscopy after injection of small amounts of contrast medium.

\section{Intraoperative manometry}

The manometric catheter was inserted through the duodenotomy incision into the papilla and gently pushed so that the tip was positioned within the bile duct.

In both cases measurements were done by the station pull through technique, withdrawing the catheter through the papilla in $2 \mathrm{~mm}$ steps under endoscopic or direct visual control.

\section{Perendoscopic sphincterotomy}

Standard perendoscopic sphincterotomy was done in 12 cases (group 4a). In eight additional patients (group 4b) with 5-10 $\mathrm{mm}$ CBD stones, the incision length was calibrated on the basis of manometry, by using a marked papillotome (Olympus Optical Co, Tokyo, Japan), with the snare close to the tip.

\section{Surgical sphincterotomy}

Partial distal sphincterotomy was followed by suture approximation of both the CBD and duodenal mucosa, according to a previously published technique. ${ }^{11-}$

\section{Analysis of SO length}

The sphincter zone was identified by the pull through technique as the zone of (a) high resting pressure between duct and duodenal pressure with (b) superimposed phasic waves. The number of successive $2 \mathrm{~mm}$ spaced black marks, observed during the pull through from the very first appearance of the proximal sphincter activity to that of duodenal pressure, was used to measure the length of the sphincter zone. To better approximate the actual length of the sphincter, $1.0 \mathrm{~mm}$, corresponding to a black mark thickness, was subtracted from the sum of marks observed during pull through.

To further check the accuracy of the measurements, perendoscopic manometry was repeated during the same session in eight randomly selected patients, by using a modified catheter, which, once positioned within the SO, enabled to record intraluminal pressures of the entire length of the sphincter without the need of the step-by-step withdrawal. This catheter had three side holes spaced either 4 or $10 \mathrm{~mm}$ apart and could detect sphincter length over a distance of 4.0 and $8.0 \mathrm{~mm}$ and, respectively, 10 and $20 \mathrm{~mm}$.

Tracings were analysed by two independent observers who were unaware of the patient's diagnosis, according to a previously published standardised method. ${ }^{13}$ The length of both the high resting pressure (HPZ), and the phasic activity zone (PAZ) were assessed. Only measurements which were identical or differed by $2 \mathrm{~mm}$ or less were taken into consideration. When the difference was more than $2.0 \mathrm{~mm}$ a third observer arbitrated.

The paired and unpaired Student's $t$ test was used to carry out statistical analysis.

\section{Results}

The results of measurements in the 5 groups are presented in Table 1 and Table 2.

The high resting pressure (HPZ) and phasic wave zone (PAZ) of the biliary sphincter were significantly longer than those of the pancreatic duct $(p<0.05)$. This was true in both group 1 and 2 subjects. In group 1 the mean CBDSO-HPZ was not statistically longer than CBDSO-PAZ, whilst the mean pancreatic HPZ was significantly longer than the PAZ $(0 \cdot 8 \pm 0.3 \mathrm{~mm}$, $\mathrm{p}<0 \cdot 05)$. Neither the CBDSO-HPZ nor the CBDSOPAZ differed between gallstone (group 3 ) and control subjects. In 12 of the group 4 patients, endoscopic sphincterotomy was carried out without knowledge of SO manometric length (4a in Table 2). After sphincterotomy mean sphincter length was reduced by $80 \cdot 6 \pm 5 \cdot 5 \%$ (mean $\pm S E$ ). In the remaining eight subjects the sphincter was bisected under manometric guidance ( $4 \mathrm{~b}$ in Table 2 ) and, mean

Table 1 Comparative biliary and pancreatic sphincter of Oddilength

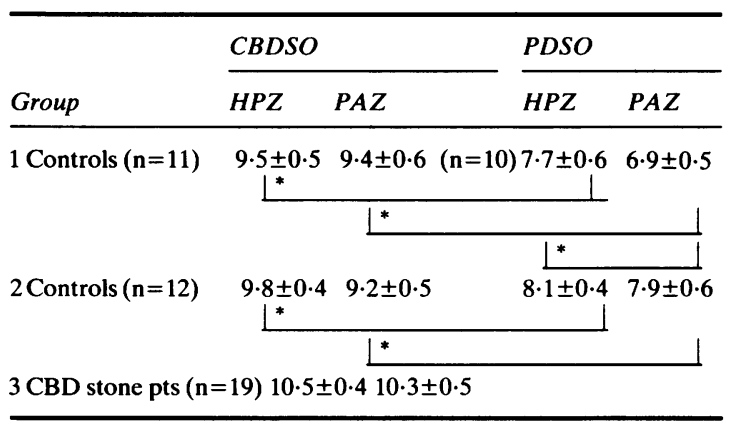

HPZ: high pressure zone; PAZ: phasic activity zone; ${ }^{*}$ p $<0.05$ mean $\pm \mathrm{SE}$; all results are in millimetres. 
Table 2 Sphincter length (HPZ) before and after sphincterotomy

\begin{tabular}{lll}
\hline Group & Before & After \\
\hline 4a Perendoscopic $(n=12)$ & $9 \cdot 0 \pm 0 \cdot 7$ & $2 \cdot 0 \pm 0 \cdot 6^{*}$ \\
4b Perendoscopic $(n=8)$ & $9 \cdot 0 \pm 0 \cdot 6$ & $0 \cdot 5 \pm 0 \cdot 3^{*}$ \\
5 Surgical $(n=11)$ & $9 \cdot 5 \pm 0 \cdot 5$ & $5 \cdot 5 \pm 0 \cdot 1^{*}$
\end{tabular}

${ }^{*} \mathrm{p}<0.001$; mean $\pm S E$ all results are in millimetres, $4 \mathrm{a}$ without, $4 \mathrm{~b}$ with manometric control.

sphincter length was reduced by $95 \cdot 2 \pm 3 \cdot 5 \%$ (Fig. 1 ). The mean difference between the endoscopically estimated sphincterotomy incision length and manometric evaluation of excised SO sphincter (expressed as the difference of the original minus the residual sphincter length) was $1 \cdot 3 \pm 0 \cdot 3 \mathrm{~mm}$ (mean $\pm \mathrm{SE}$ ).

The original sphincter length was not affected by surgical incision in two of 11 cases and was reduced by only $4 \mathrm{~mm}$ or less in another five of 11 cases. Mean sphincter length was reduced by $46 \cdot 7 \pm 10 \cdot 3 \%$ (Fig. 2).

\section{MEASUREMENTS BY THE CONVENTIONAL AND} MODIFIED CATHETERS

Sphincter length, measured in eight selected subjects by $2 \mathrm{~mm}$ and $\mathrm{a}$ or $10 \mathrm{~mm}$ spaced side holes catheter was $6.9 \pm 0.6$ and $6.9 \pm 0.5 \mathrm{~mm}(\mathrm{M} \pm \mathrm{SE})$, respectively. Measurements derived by step withdrawal and by

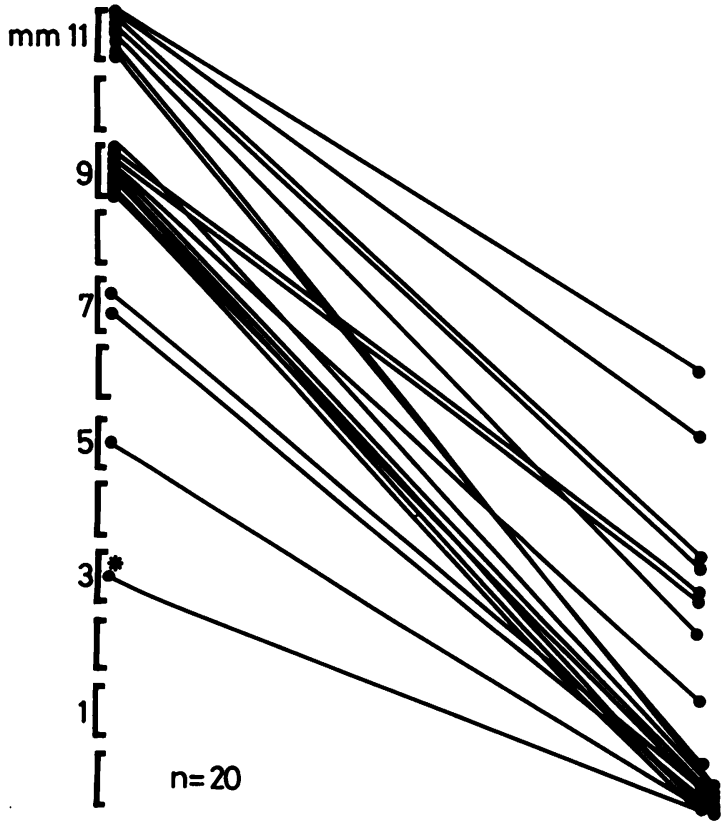

Fig. 1 Common bile duct sphincter length before and after perendoscopic sphincterotomy. ${ }^{*}$ previously submitted to surgical sphincterotomy.

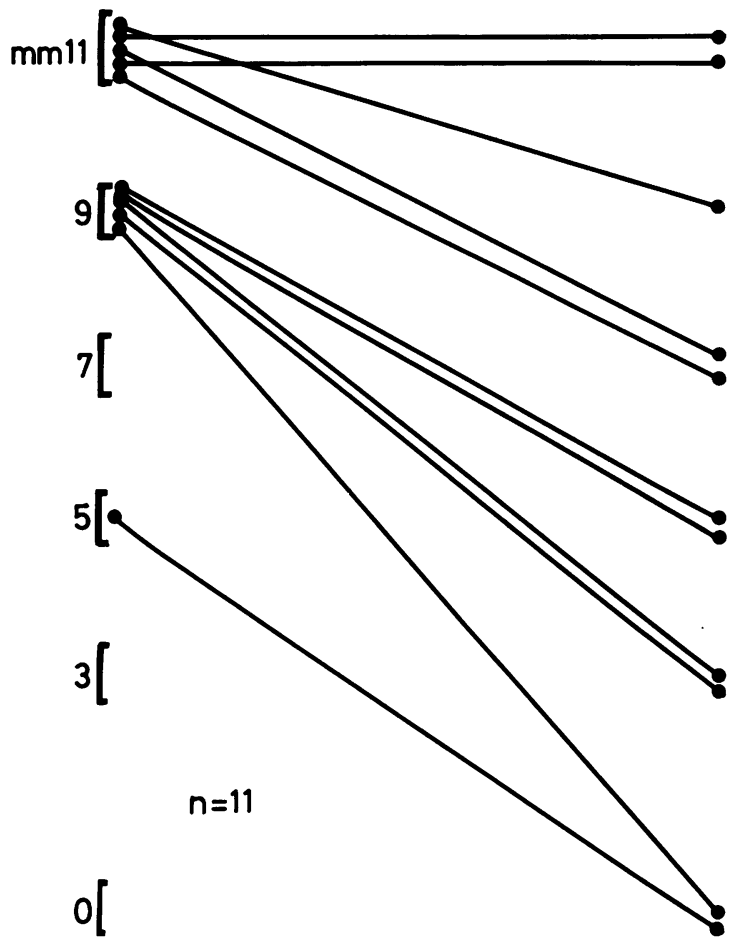

Fig. 2 Common bile duct sphincter length before and after surgical partial sphincterotomy.

stationing of the catheter were superimposable (mean difference between the two recordings $0.5 \pm 0.2 \mathrm{~mm}$, range $0-2 \mathrm{~mm} ; \mathrm{r}=0.88, \mathrm{p}=0.02$ ) (Fig. 3).

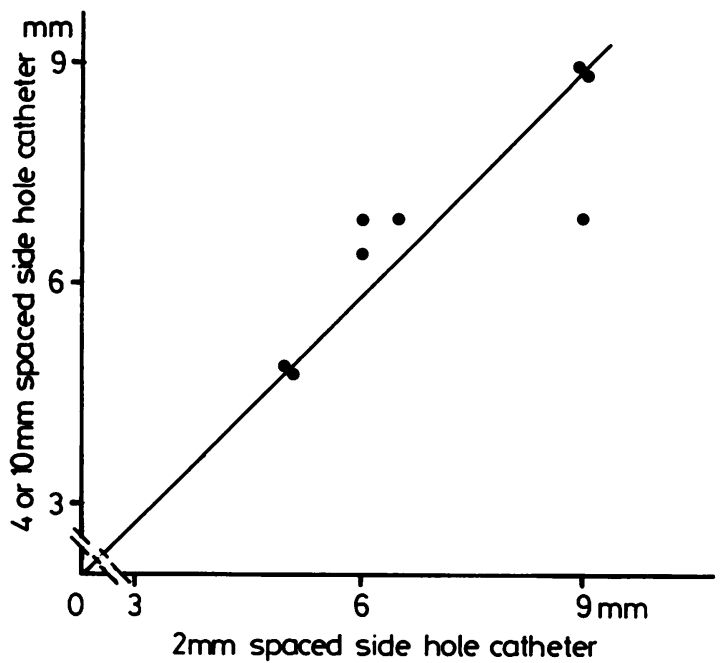

Fig. 3 Comparison between sphincter length measurements derived from $2 \mathrm{~mm}$ and 4 or $10 \mathrm{~mm}$ spaced side hole catheter $(r=0 \cdot 88, p=0 \cdot 02)$. 


\section{Discussion}

Manometrically, a resting high pressure zone (HPZ) can be detected at the distal end of the common bile and pancreatic duct, including the common channel when present, and its extent may be considered as the physiological length of the sphincter. Unlike other sphincters, however, the SO also shows a phasic motor activity, so that the extent of HPZ can be compared with that of the phasic activity zone (PAZ).

In the present study the biliary and pancreatic SO length was evaluated, and only recordings in which the extent of both HPZ and PAZ could be measured were taken into consideration. To reduce measurement error during withdrawal of the catheter, the very first appearance of the black ring at the papillary orifice was detected and used as a reference point for length evaluation. Possible measurement errors caused by altered catheter sphincter spatial relationships during successive step withdrawals, appeared to be negligible, as shown by the superimposable data obtained by the 2,4 , and $10 \mathrm{~mm}$ spaced side hole catheters. A standardised reading method ${ }^{13}$ was used, and only data with a total or concorded agreement between independent observers were taken into account.

At the level of the CBD-SO no statistically significant difference was found between HPZ and PAZ measurements, suggesting that both can be used to evaluate the physiological length of the CBD sphincter. At the level of the PD-SO, the HPZ resulted more extended proximally than the PAZ.

Intra- and inter-subject comparative measurements confirmed anatomical observations,${ }^{58}$ showing that the pancreatic sphincter is significantly shorter than the choledochal one. The physiological length of both the pancreatic $(7 \cdot 7 \pm 0.6 \mathrm{~mm})$ and the biliary sphincter $(9.5 \pm 0.5 \mathrm{~mm})$, however, were shorter than their reported anatomical length. ${ }^{5-10}$ A possible explanation of this discrepancy is that the upper limit of sphincter muscle cells, around the circumference of the ducts, is not abrupt, but instead tapers off gradually. ${ }^{9}$ Moreover, anatomical measurements usually refer to the papillary pore as the lower limit of the sphincter, and it has recently been reported ${ }^{8}$ that there are no sphincter muscle cells in the distal $2 \mathrm{~mm}$ of the common channel.

No significant differences in length of the sphincter were found between CBD stone patients and controls. A wide distribution in the residual sphincter length was observed after partial surgical sphincterotomy, ${ }^{12}$ and this was confirmed by intraoperative measurements, when the extent of the section, as reported by the surgeon, was compared with the actual section deduced by manometry - that is, the original minus the residual sphincter length. Less variable results were obtained when sphincterotomy was done under manometrical guidance; likewise SO endoscopic excision can be tailored according to manometric measurements of the physiological sphincter length.

Results of the present study could therefore suggest that manometric estimate of the sphincter length may be of help during sphincterotomy, whether surgical or endoscopic.

Whether or not sphincterotomy carried out under the manometric guidance represents a valuable alternative to standard sphincterotomy, remains to be established, however, and will require careful prospective studies.

This work was supported in part by the CNR, grant $\mathbf{n}$ CT 85.00765.04 and in part by a grant of the Ministry of Public Education. A preliminary communication of this work appeared as an abstract in Gastroenterology 1986; 90: 1669.

\section{References}

1 Geenen JE, Hogan WJ, Dodds WJ, Stewart EJ, Arndorfer RC. Intraluminal pressure recording from the human sphincter of Oddi. Gastroenterology 1980; 78: 317-24.

2 Carr-Locke DL, Gregg JA. Endoscopic manometry of pancreatic and biliary sphincter zones in man. Basal results in healthy volunteers. Dig Dis Sci 1981; 26: 7-15.

3 Toouli J, Geenen JE, Hogan WJ, Arndorfer RC. Sphincter of Oddi motor activity: a comparison between patients with common bile duct stones and controls. Gastroenterology 1982; 82: 111-7.

4 De Masi E, Corazziari E, Habib FI, et al. Manometric study of the sphincter of Oddi in patients with and without common bile duct stones. Gut 1984; 25 : 275-8.

5 Rettori R. Étude morphologique du système musculaire de la jonction choledocho-pancreatico-duodenale et bases anatomiques de la section du sphincter d'Oddi. Presse Méd 1956; 51: 1208-11.

6 Boyden EA. Anatomy of choledochal junction in man. Surg Gynecol Obstet 1957; 104: 641-52.

7 Barraya L, Pujol Soler R, Yvergneaux JP. La region Oddienne. Anatomie millimetrique. Presse Méd 1971; 55: 2527-34.

8 Flati G, Negro P, Flati D, Porowska B, Gondio E, Marinozzi G. Measurement of sphincter of Oddi length in anatomical specimens. Ital J Gastroenterol 1985; 17: 329-32.

9 Hand HB. An anatomical study of the choledochoduodenal area. Br J Surg 1963; 50: 486-94.

10 Velasco Suarez C. Structure of the major duodenal papilla. M Sinai J Med NY 1982; 49: 31-7.

11 Speranza V, Lezoche E, Minervini S, Carlei F, Basso N, Simi M. Transduodenal papillostomy as a routine procedure in managing choledocholitiasis. Arch Surg 1982; 117: $875-8$. 
12 Torsoli A, Biliotti D, Habib FI, et al. Common bile duct stones and sphincter of Oddi function. Ital J Gastroenterol 1986; 18: 109-11.
13 Corazziari E, Habib FI, Biliotti D, et al. Reading error and time variability of sphincter of Oddi (SO) recordings. Ital J Gastroenterol 1985; 17: 343-7. 